\title{
Piston assembly in the most powerful 2.01 diesel engine - case study of the current tribological system and innovative concepts for the future
}

This article is a contribution to the ongoing debate on the scenario of the vehicle powertrains development. The directions of the internal combustion engines development in search of the possibility of effective economic and ecological indicators improvement have been indicated. It has been pointed out that this goal can be achieved through the use of nanotechnology in order to exceed the downsizing barriers resulting from the permissible mechanical loads for conventional materials. The article presents the study of the construction and materials used in the piston assembly of the most advanced four-cylinder, compression-ignition diesel engine currently in manufacture. Original concepts of nanotechnology have been proposed to reduce friction losses in major friction components of future engines with extremely high loads. The main idea is to verify the hypothesis that the sub-micron surface texture of the friction components obtained in the process of applying anti-wear outer layers can lead to an effective reduction of friction losses under real engine operating conditions. Computer simulations of the effects of introducing the surface texture in the upper sealing ring on friction loss confirm this hypothesis by showing friction value being reduced by 3-4\% relative to the standard ring profile. In the summary, further advanced technologies designed to effectively utilize the unique properties of carbon nanotubes have been described.

Key words: piston engine, powertrains development, tribological system

\section{Introduction}

The production of the VW Golf with a diesel engine started in 1976. It was the first popular car with this type of engine. This construction was the response to the oil crisis after 1973. The $1.5 \mathrm{dm}^{3}$ displacement combustion engine with a swirl chamber was characterized by a limited power of $37 \mathrm{~kW}$ and a maximum torque of only $80 \mathrm{Nm}$, but it offered extremely low fuel consumption. In subsequent years, the engine was improved, increasing the displacement and introducing turbocharging, while other manufacturers began mass-producing competing cars with similar engine designs. A major breakthrough came in 1989 when a supercharged diesel engine and direct fuel injection system were successfully introduced into production. Subsequent generations of the CI engines were characterized by increasing unit power and torque indexes, while consuming much less fuel than comparable SI motors (Fig. 1).

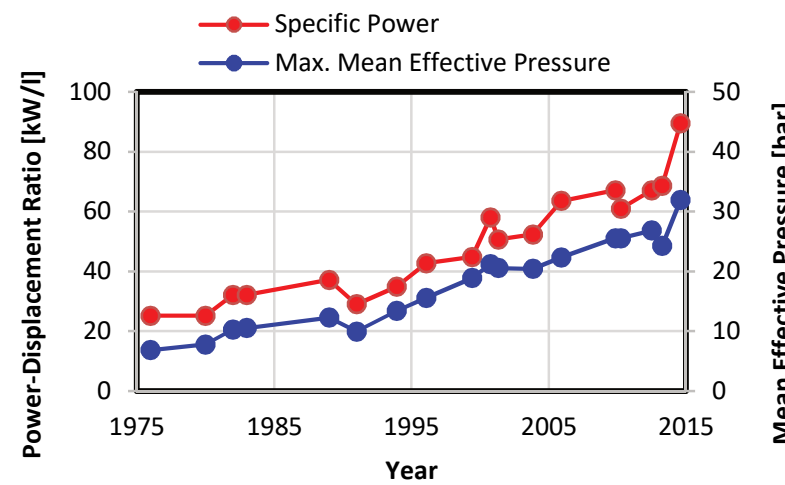

Fig. 1. Development of CI engines on the example of VW engines; mean effective pressure and specific power
CI engines have become an increasingly popular source of automobile propulsion. In some European countries more cars with CI engines were purchased than with SI engines.

At present, the share of CI engines in the market of new cars sold in Europe is somewhat limited, which is due to the cost of production of complex exhaust gas aftertreatment systems. However, such engines are still needed in order to meet the carbon dioxide reduction target, among other reasons.

\subsection{The role of the $\mathrm{IC}$ engines in the future}

Reciprocating internal combustion engines have been used in car drives for over a hundred years, but in recent years there has been a growing tendency to replace them with electric motors. These types of efforts are politically motivated or dictated by fashion - ecology and modernity, but are devoid of rational technical justification. It is also worth noting that neither the electric nor hybrid vehicles can be regarded as an invention of modern times.

Road transport is one of the main sources of carbon dioxide and toxic air pollutants emissions. Air pollution continues to be a problem, especially in large cities, demanding an urgent solution. In this case the elimination of vehicles with combustion engines from city centers and replacing them with electric drive buses and taxis is an effective solution that can be quickly implemented. Such actions make sense, if they are local in nature, but striving for global replacement of combustion engines with electric motors as quickly as possible makes no sense. Well-to-wheel analysis indicates that as long as electricity is produced mainly in power plants burning fossil fuels the replacement of automotive internal combustion engines with electric motors 
will not bring a radical improvement in transport ecology. Currently about $67 \%$ of globally generated electricity is produced in power plants through the burning of fossil fuels. The development of renewable energy sources does not even compensate for the power lost due to nuclear power plants shut offs, as a result the share of energy derived from fossil fuels does not even decrease [20].

In the case of electric cars the unfavorable ratio of stored energy to the battery mass remains an unsolved problem. If coordinated action is planned and initiated the challenging technical task of dramatically increasing the battery energy concentration could be realized in the future; as in the past a clearly defined plan allowed building a vehicle in a few years that allows man to fly to the moon.

An alternative to the search for solutions to increase the energy concentration on board the electric vehicles is to improve the existing internal combustion engines. The authors believe that when determining further directions of automotive industry development the first consideration to take into account is the ratio of the expected benefits to the cost of a project and not its ambition. In this context, it is reasonable to strive for improvements to internal combustion engines; where the ecological and economic aspects play a special role. The environmental performance cannot, however, be seen as a formal meeting of the current tests requirements, but to ensure that the actual emission of toxic compounds is as small as possible in all operating conditions [14-16]. LCA analysis is an important issue [11].

\subsection{Future requirements in the piston assembly of $\mathrm{CI}$ engines}

At present, the downsizing trend is evident in the design of passenger car engines [9], Fig. 1. In the author's view, the downsizing limits will continue to shift in order to achieve the benefits of improved engine efficiency and reduced fuel consumption [12]. This is due to increased thermal and mechanical loads in the piston assembly. The constantly increasing power of the engines causes the piston's bottom to be heated to the limits of the aluminum alloy durability, thus replacing aluminum with steel is considered $[1,2,4,18]$.

Another important factor is meeting the requirements for toxic gas emissions. In order to reduce the emission of nitrogen oxides in CI engines, exhaust gas recirculation (EGR) and injection delay in high engine load conditions are common (Fig. 2). However, this action inevitably leads to delays in the combustion process, high cylinder pressure occurs when the piston is already far from the TDC in the stroke. The normal pressure of the piston pushing on the cylinder walls increases considerably as a result. Attention is increasingly paid to new materials capable of reducing friction in mixed lubricating regime, and to prevent seizure of the piston in the cylinder [4-7].

In this article, the authors wish to pay particular attention to the tribological benefits of applying texture on the surface of the piston assembly elements. In this context, the results of the work presented in $[10,21]$ are promising. Surface textures can be obtained as a side effect of applying standard top layers with proven beneficial tribological properties, such as chromium and magnesium phosphate.

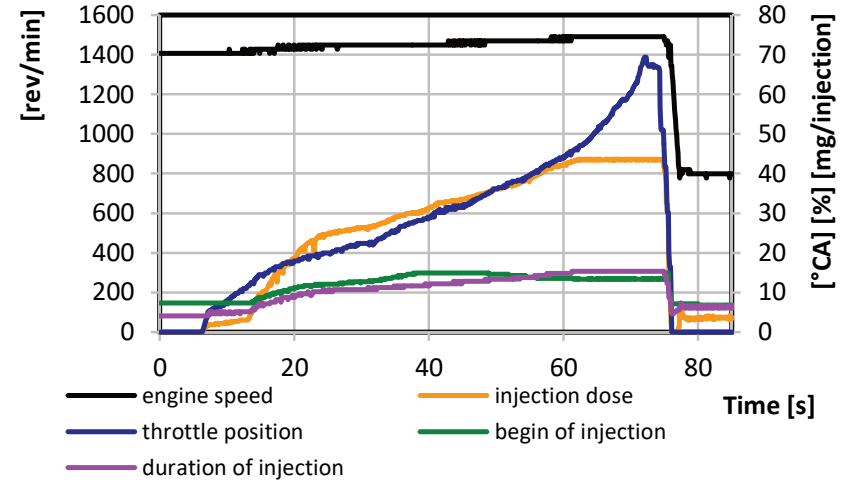

Fig. 2. Injection timing of the CI engine as a function of the engine load; engine type: Volkswagen AXD [12]

\section{Piston design for the 2.01 Diesel engine with the highest specific power}

All the research results presented in this article are only for the elements of the twin turbocharged 2.01 TDI BiTurbo engine from Volkswagen. With an output of $176 \mathrm{~kW}$ at $4,000 \mathrm{rpm}$ and $500 \mathrm{Nm}$ of torque from 1,750 to $2,500 \mathrm{rpm}$, it has a specific power of $88 \mathrm{~kW} / \mathrm{l}$. This means the new Volkswagen engine achieves the highest specific power of all four-cylinder series-production diesel engines. A compact charging assembly with two turbochargers enabling charge absolute pressures of up to $0.38 \mathrm{MPa}$ is a characteristic aspect of this engine. A further major innovation with respect to extremely efficient combustion is the commonrail injection system with piezoelectric injectors for injection pressures of $250 \mathrm{MPa}$. The crankcase, crankshaft, conrods and pistons have been reinforced for the combustion pressure of $20 \mathrm{MPa}$. The general outline of the engine design was discussed by the manufacturer in [8], Figure 3 shows the cross section of the engine piston.

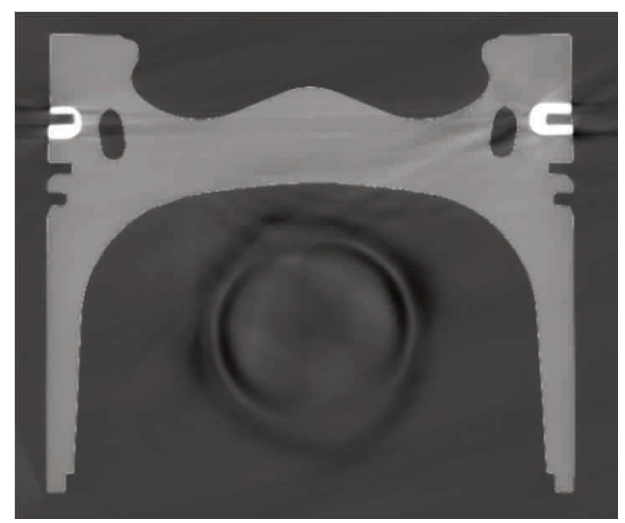

Fig. 3. Cross section of the VW TDI engine piston, with a displacement of approximately $2 \mathrm{dm} 3$ and a maximum power of $176 \mathrm{~kW}$, the picture obtained in a computer tomography

\section{Piston assembly friction components - materials and surfaces}

\subsection{The piston}

The crankcase of the engine is cast in GJL-250. Aluminum pistons were used in the engine (Fig. 4), on which bowl-rim remelting further increases hardness in the areas subject to highest loads [8]. As with the weaker versions of the engines, piston pins with a DLC layer are used in con- 
junction with bronze sleeves embedded in the piston. There is a standard oil cooler in the piston and an insert around the upper ring (cf. Fig. 3). The lateral surfaces of the piston are covered with anti-friction lacquer, as in most modern engines. Topography of the lacquer surface is shown in Figure 5 as SEM images recorded with secondary electrons (SE) and back scattered electrons (BSE). The EDS analysis of this surface is shown in Fig. 6. Particularly the BSE image indicates that the lacquer has a composite structure with embedded particles ranging in size from a few to several micrometers.

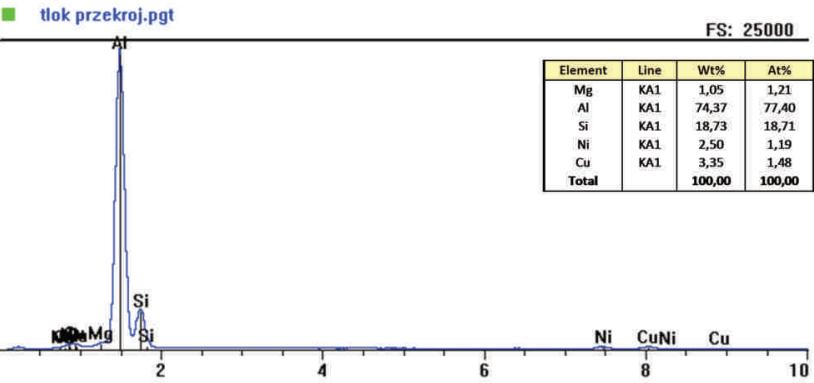

Fig. 4. EDS analysis of piston material

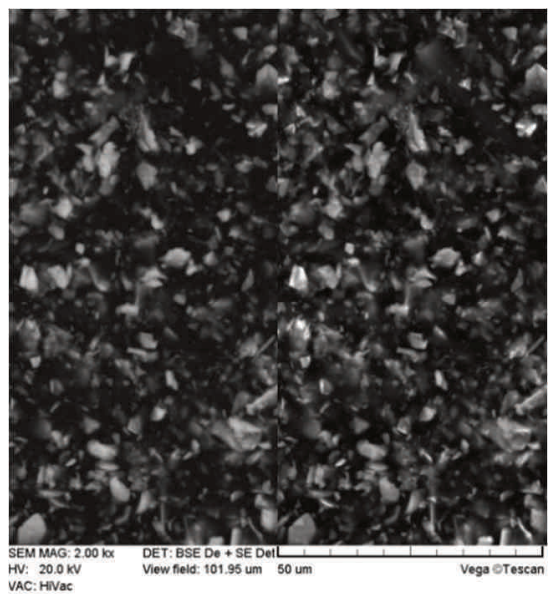

Fig. 5. Antifriction lacquer layer on the piston lateral surface in SEM image recorded by secondary electrons (left) and back scattered electrons (right); The sample was taken from a new piston that was washed with acetone in an ultrasonic bath

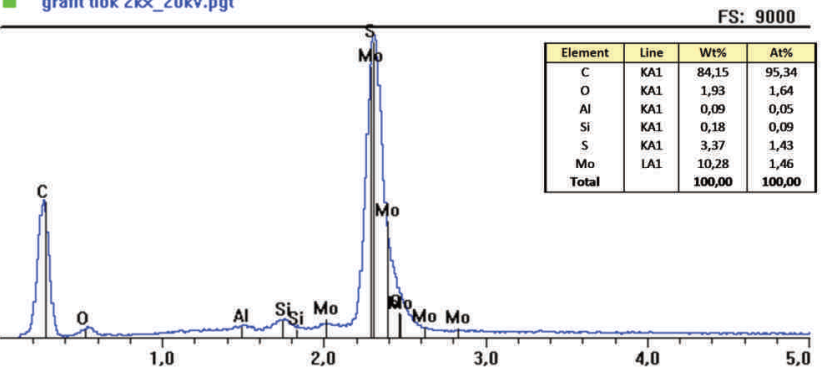

Fig. 6. EDS analysis of the sample shown in Fig. 5

\subsection{Upper sealing ring}

The upper sealing ring is covered with a chromium layer clearly visible on the SEM image and identified by EDS analysis (Fig. 7 and Fig. 8).

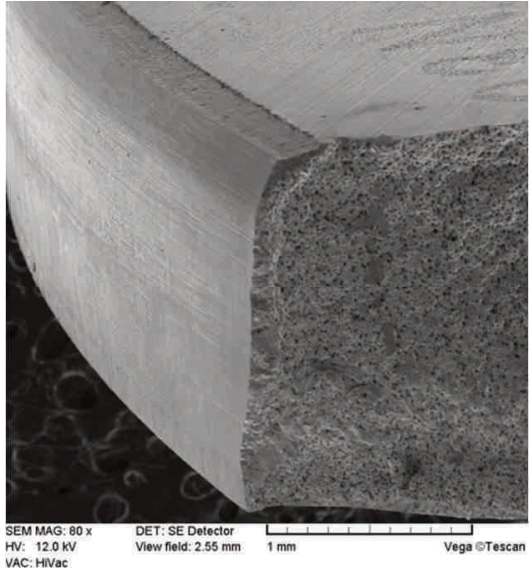

Fig. 7. Upper sealing ring cross section SEM image

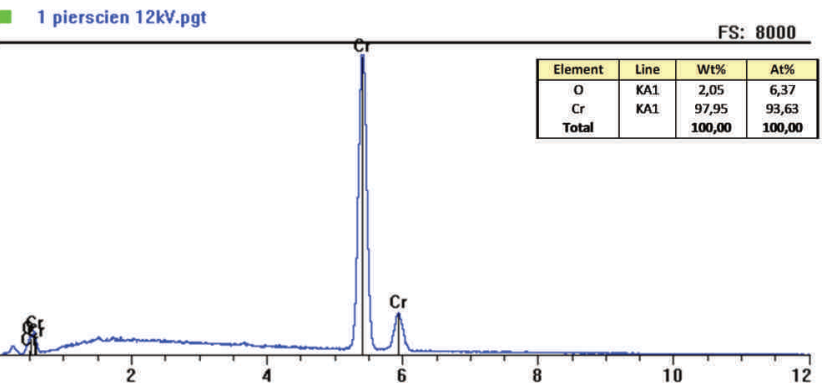

Fig. 8. EDS layer analysis on the upper sealing ring slide surface

\subsection{The second piston ring}

The second piston ring is shaped as a taper-faced Napier ring. The sliding surface of the ring is doped with zinc phosphate, forming characteristic structures exhibiting a certain degree of axial symmetry. Results of the tests using the electron microscope are shown in Figures 9 and 10.

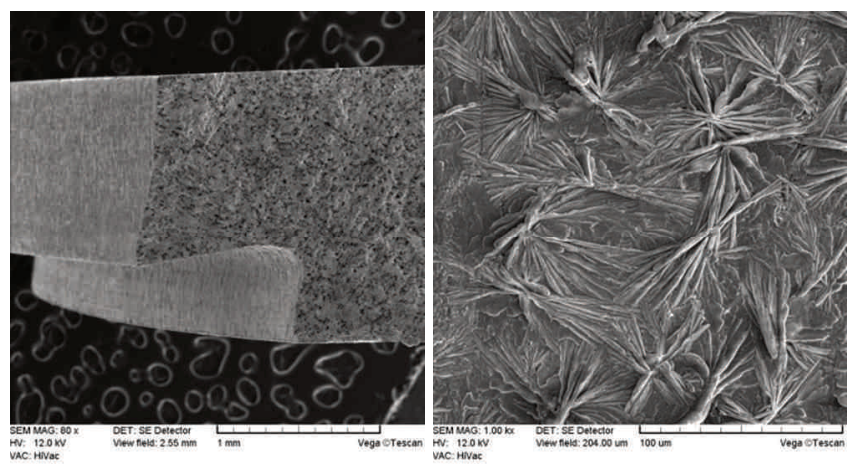

Fig. 9. Images of second ring recorded with SEM microscope; a crosssection view and a closeup on the sliding surface

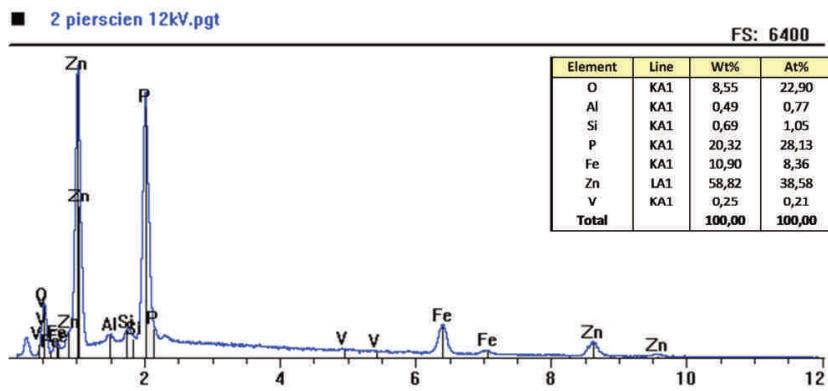

Fig. 10. EDS sliding surface analysis of the second ring 


\subsection{The third piston ring}

The third piston ring is a double-beveled ring with spiral-type expander.

The SEM imaging results of the scraper ring are shown in Figures 11 and 12, same as previously. As in all other cases, new ring samples were used, that have never been installed in an engine; these samples were washed in acetone and sonicated.
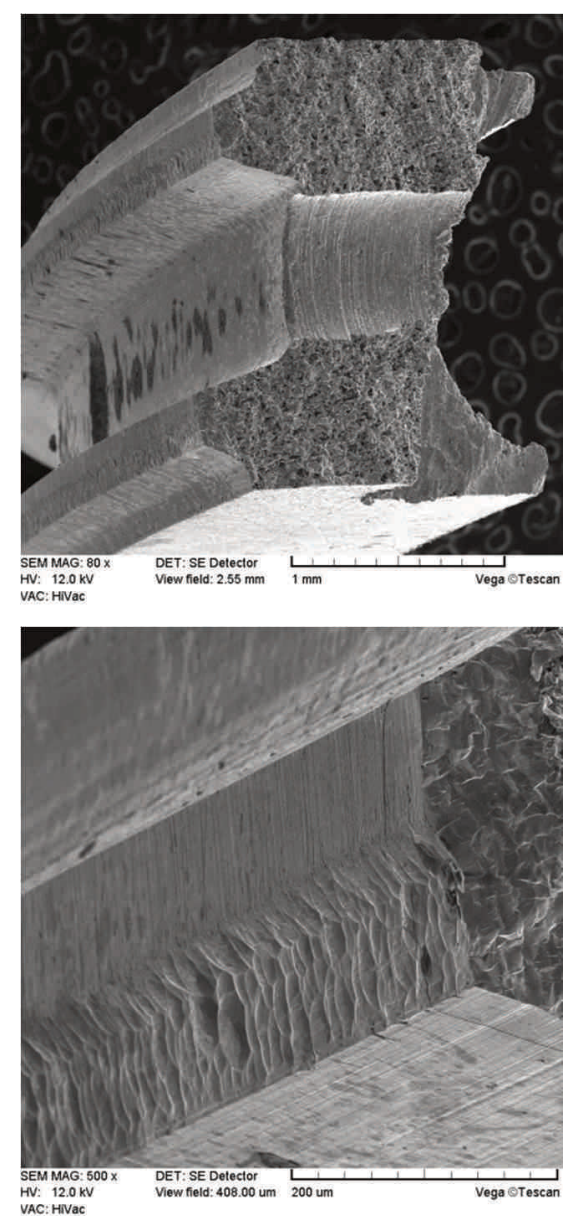

Fig. 11. The images of the third piston ring recorded with the SEM microscope; a cross-section view and a closeup on the sliding surface

(1- 3 pierscien $12 \mathrm{kV} \cdot \mathrm{pgt}$

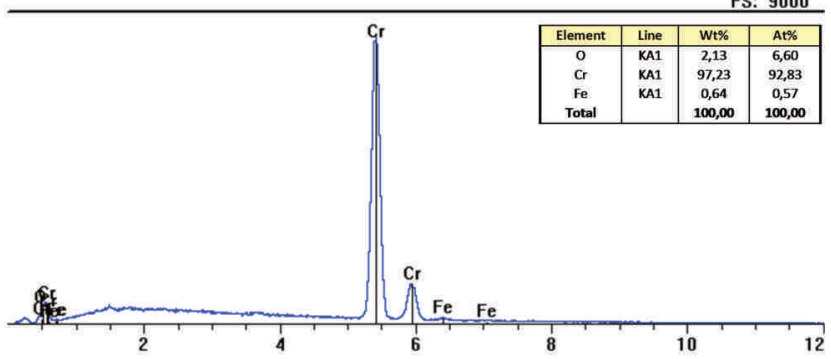

Fig. 12. EDS analysis of sliding surface of the third piston ring

\section{Texturized surface - friction estimated by computer simulation}

In order to investigate the use of the rings sliding surface textures for friction reduction in the main friction components of the piston engine, numerical simulations were performed using the MAHLE-VTL (Virtual Tribology Laboratory) program.

The principle of operation of the program uses a onedimensional model of two friction surfaces, which allows to evaluate phenomena related to friction losses and oil film parameters. The program performs numerical calculations based on the classic Reynolds equation as well as the Greeenwood and Tripp equation. The mathematical model has been implemented in a program that enables numerical simulations. The simulation results include, among other things, the following parameters as a function of the crankshaft angle: minimum oil film thickness, friction coefficient and hydrodynamic pressure between the ring and the cylinder wall. Despite the constraints of a one-dimensional model, the program can be used as a virtual tool for analyzing the effects of changing ring profiles that affect mixed friction conditions [19].

Simulations were made for the spherical serial piston ring profile, then for an experimental surfaces with microgrooves providing favorable tribological properties. The inspiration for defining the shape of the microgrooves was the shape of the surface observed on the Volkswagen TDI engine piston ring, Fig. 13. (See also Fig. 11). Profiles adopted in the simulation program are shown in the Fig. 14.

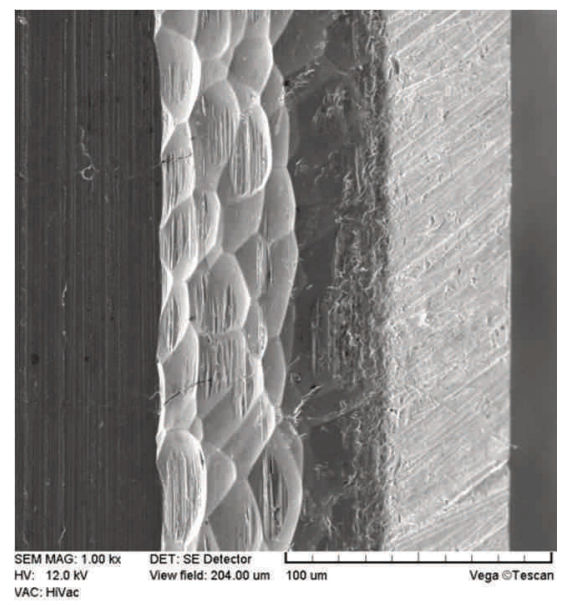

Fig. 13. Surface structure on the engine piston sealing ring of the Volkswagen TDI engine used as an inspiration for profiles adopted in numerical simulations; image recorded with SEM microscope,

Simulations were carried out for the characteristic dimensions and VW TDI engine top sealing ring operating conditions. The engine was discussed earlier in this article. To understand the effects of surface texture of the ring, the simulations were carried out for two characteristic engine operating points:

- engine idle,

- high load: (cylinder pressure $25 \mathrm{MPa}$, rotational speed $2000 \mathrm{rpm})$.

In Figures 15 and 16 the simulation results of the ring with microgrooves showed the greatest reduction in friction with respect to the serial ring.

The highest oil film capacity was obtained in the variant with the smallest microgroove width, i.e. the highest groove density (variant 2). 

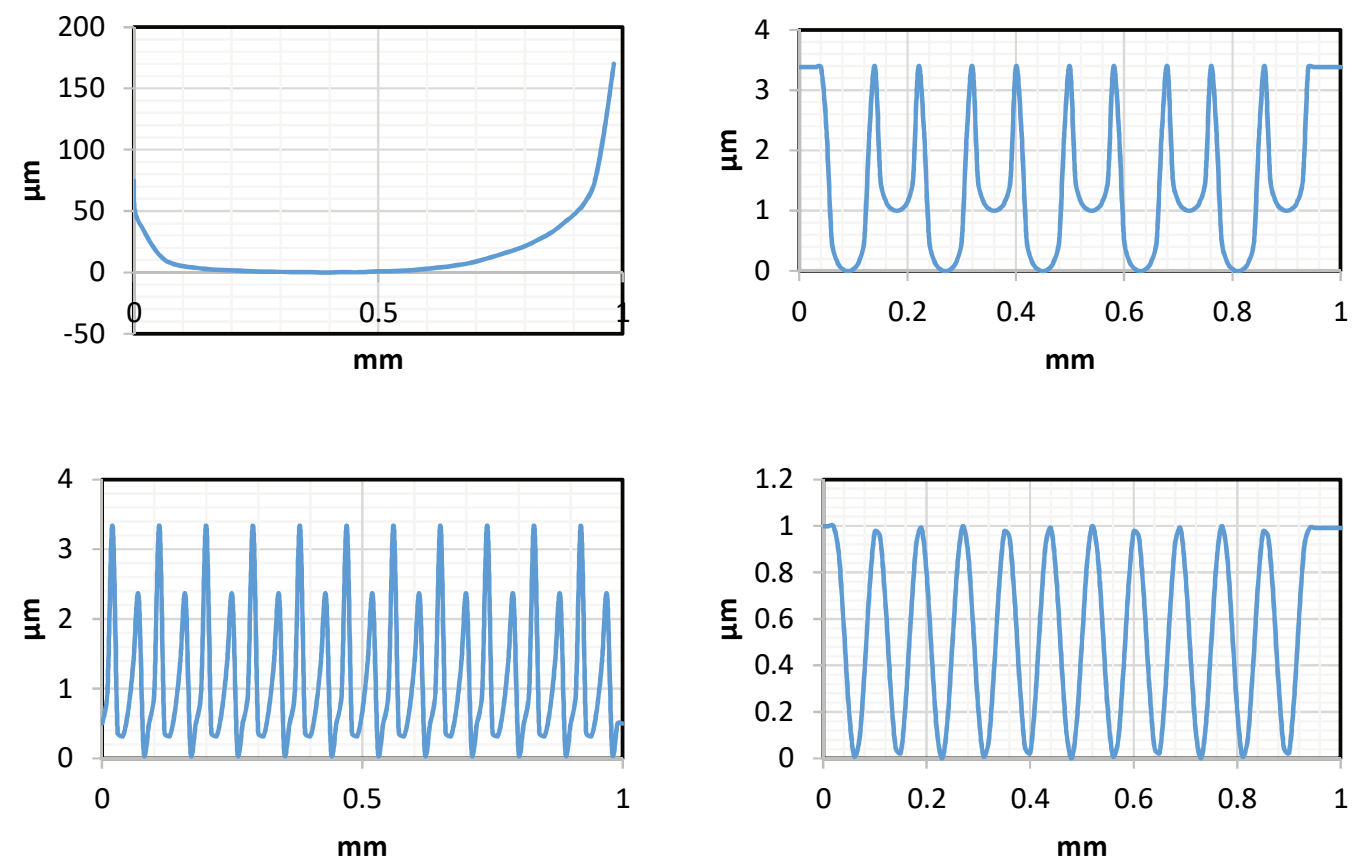

Fig. 14. Shape of sliding surface of rings adopted in the simulation program; standard ring profiles (top left - variant 1), and subsequent versions of profiles with microgrooves used in the simulations (top right - variant 2, bottom left - variant 3 , bottom right - variant 4)
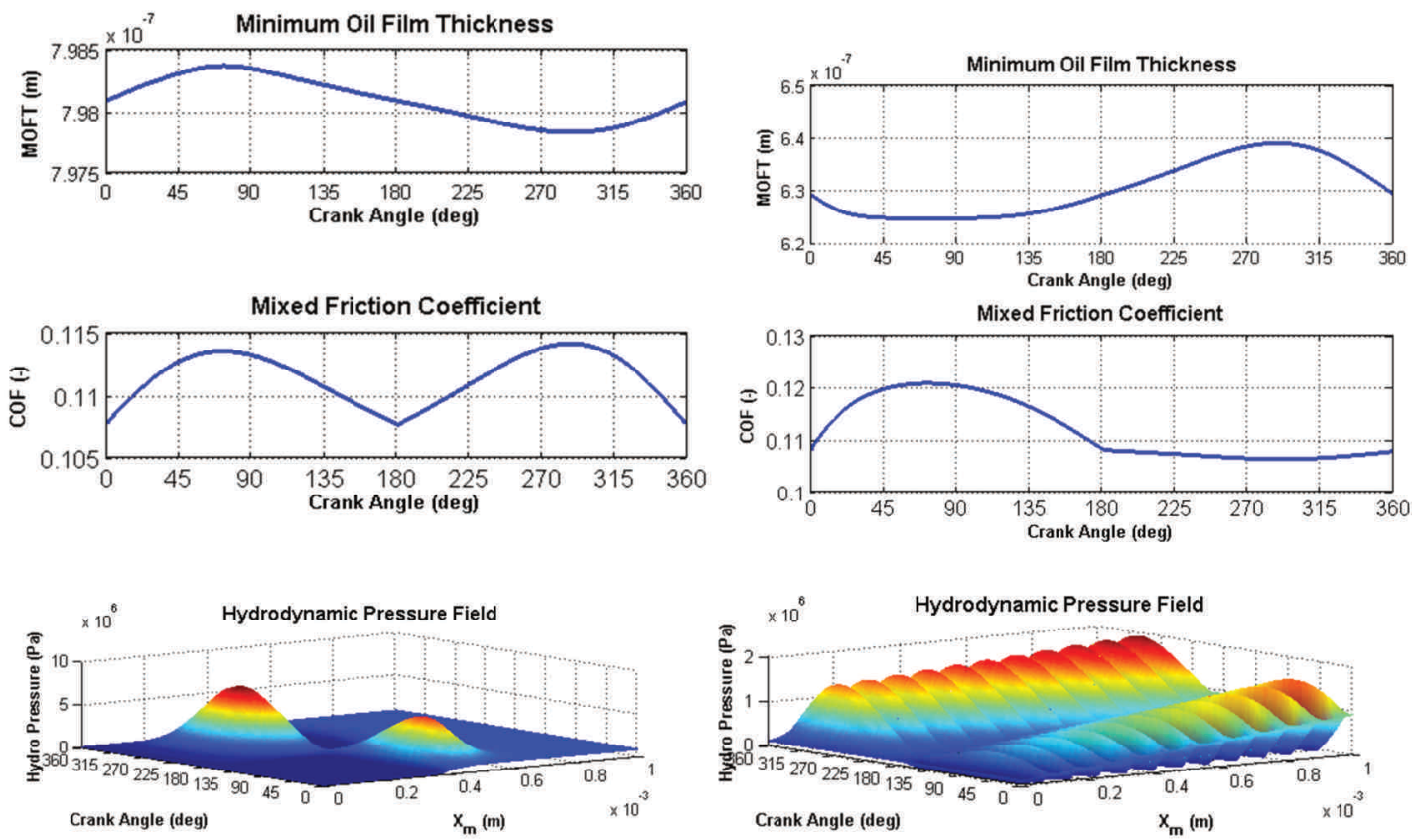

Fig. 15. Simulation results - selected engine idling parameters; serial profile ring (left), ring with added texture (right)

The existence of microgrooves results in a hydrodynamic load due to cavitation that occurs around the divergent portion of each groove. The formation of hydrodynamic pressure even in flat areas between each microgroove is particularly interesting. This effect is due to the non-zero pressure observed on each side of the groove, whereby the intermediate flat areas behave like linear pressure distribution bearings.

Applying textures on all experimental piston ring variants gave a higher hydrodynamic capacity of the oil film than the standard profile while reducing friction by about 3 $4 \%$. It is particularly important that these effects can be observed at high engine loads. The results show the need for further, extended research of the hydrodynamic effects obtained for more complex shapes of textured surfaces. In this case, however, it is necessary to use a calculation program equipped with additional functions, taking into account the effect of two dimensional flow, the effect of inertia and the effect of surface roughness on the lubricating oil flow. 

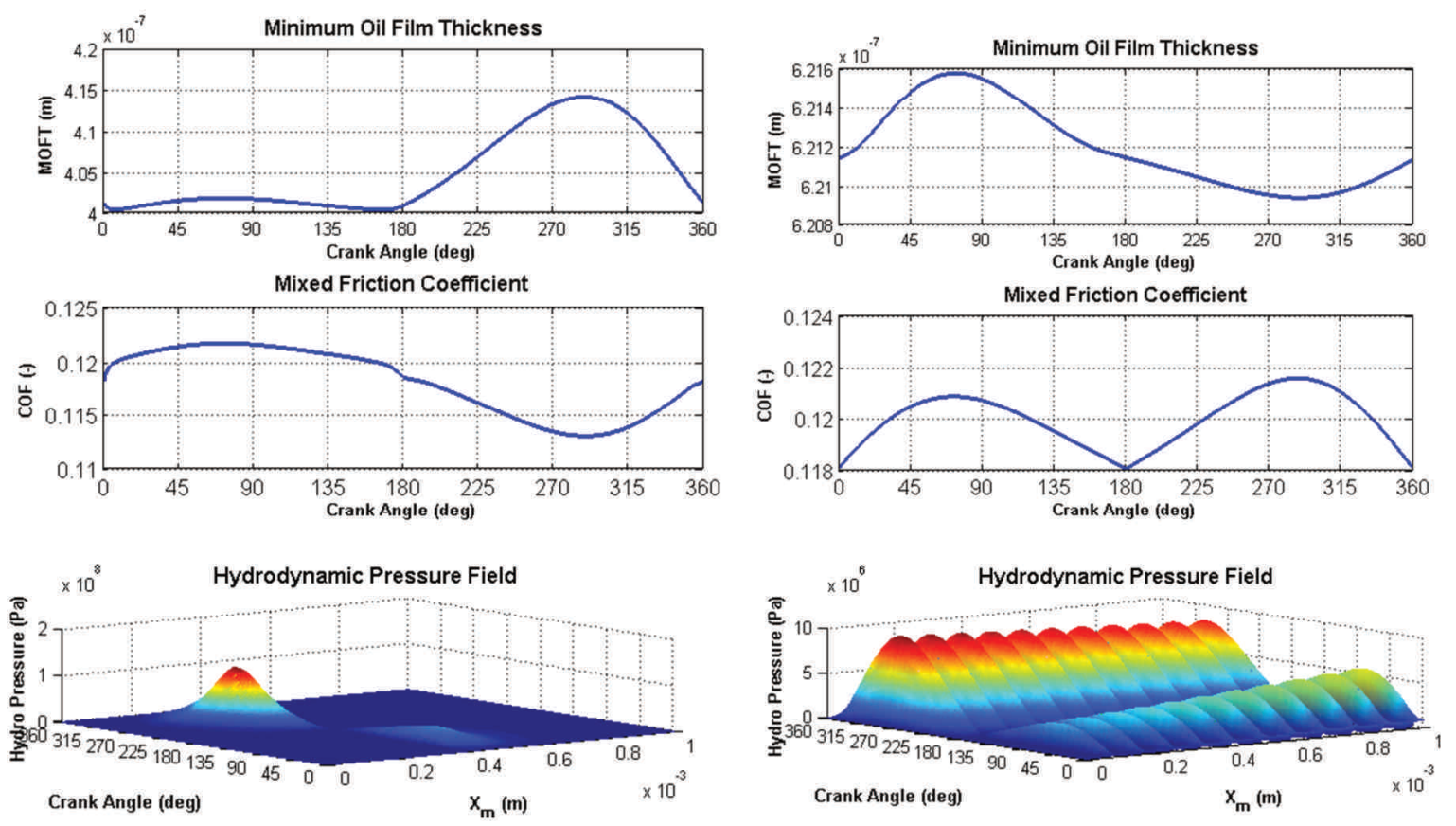

Fig. 16. Simulation results - selected maximum engine load parameters; serial profile ring (left), ring with added texture (right)

\section{Summary and conclusions}

1. The objective technical analysis validates the expectation that piston-type internal combustion engines will play a dominant role as a source of propulsion for cars. At the same time, potential for improving the environmental performance of subsequent generations of combustion engines is indicated. The use of new materials, in particular nanomaterials and nanotechnologies, is a particularly attractive area of improvements. Reducing the negative impact of car engines on the environment can be achieved by shifting the downsizing limits towards higher loads, while using new construction materials with properties superior to conventional materials.

2. For the future engines, it is particularly important to shape the friction layers in order to increase the thermal and mechanical loads. The coating layers on the friction surfaces of the piston assembly should effectively reduce friction, especially in the mixed friction regime.

3. The research allowed for a visualization of the different microstructures present on the piston assembly friction components surfaces of the four-cylinder CI engine with the highest power output among the mass-produced engines. The formation of such structures can be treated as a characteristic feature or even as a side effect of the applied technology of applying top layers. The authors propose a reverse approach assuming that the texture on the piston assembly friction surfaces can contribute to the reduction of engine friction losses.

4. The preliminary simulations of the piston assembly friction conditions have confirmed the validity of the accepted hypothesis. It has been shown that by replacing the smooth surface of the piston ring with a defined texture surface, a reduction in friction loss of 3-4\% can be achieved.

5. The conducted computer simulations can be considered as an introduction to a broader program of finding optimal surface configurations.

6. The use of hierarchical nanostructures, described in [17, 22], can be extended to the conceptual design of the microtexture. In previous investigations, the authors have shown that the addition of carbon nanotubes dispersed in oil reduces friction losses [13]. In the context of earlier results, it may also be interesting to look for a synergistic texture effect on the nanoparticle oil lubricated sliding surfaces.

\section{Nomenclature}

DLC diamond-like-carbon

EDS electron dispersive spectroscopy
LCA life cycle assessment

SEM scanning electron microscope

\section{Bibliography}

[1] BABERG, A., FREIDHAGER, M., MERGLER, H., SCHMIDT, K. Aspekte der Kolbenmaterialwahl bei Dieselmotoren. MTZ. 2012, 12.

[2] BACKHAUS, R. Kolben aus Stahl für Pkw-Dieselmotoren. MTZ. 2009, 12.
[3] BLÜMM, M. et al. Innovative Schaftbeschichtungen für Otto- und Dieselmotorkolben. MTZ. 2016, 2.

[4] BUSCHBECK, R. et al. Innovative Kolbensystemlösungen für Verbrennungsmotoren. MTZ extra.

[5] DEUSS, T., EHNIS, H., BASSET, M., BISORDI, A. Reibleistungsmessungen am Befeuerten Dieselmotor - Zyklusrelevante $\mathrm{CO}_{2}$-Ersparnis. MTZ. 2011, 12. 
[6] DEUSS, T., EHNIS, H., FREIER, R., KÜNZEL, R. Reibleistungsmessungen am Befeuerten Dieselmotor - Potenziale der Kolbengruppe. MTZ, 2010, 5.

[7] DEUSS, T., EHNIS, H., ROSE, R., KÜNZEL, R. Reibleistungsmessungen am Befeuerten Dieselmotor - Einfluss von Kolbenschaftbeschichtungen. MTZ. 2011, 4.

[8] EICHLER F. et al. The New 2.01 4-Cylinder BiTurbo TDI ${ }^{\circledR}$ Engine from Volkswagen. 23. Aachener Kolloquium Fahrzeug- und Motorentechnik, 23th Aachen Colloquium Automobile and Engine Technology, Aachen, DE, 6.-8. Okt, 2014.

[9] GOLLOCH, R. Downsizing bei Verbrennungsmotoren; Ein wirkungsvolles Konzept zur Kraftstoffverbrauchssenkung. Springer-Verlag, Berlin-Heidelberg, 2005.

[10] GROPPER, D., WANG, L., HARVEY, T.J. Hydrodynamic lubrication of textured surfaces: A review of modeling techniques and key findings. Journal of Engineering Tribology.

[11] KAŁUŻNY, J., MERKISZ, J., GALLAS, D. et al. An innovative system for piston engine combustion with laserinduced ignition of the hydrocarbon fuel consisting carbon nanotubes. Combustion Engines. 2017, 168(1), 3-14.

[12] KAŁUŻNY, J. Eksperymentalne zastosowania nanorurek węglowych w konstrukcji tłokowego silnika spalinowego. Wydawnictwo Politechniki Poznańskiej. 2013.

[13] KAŁUŻNY, J., MERKISZ-GURANOWSKA, A., GIERSIG, M., KEMPA, K. Lubricating performance of carbon nanotubes in internal combustion engines - engine test results for cnt enriched oil. IJAT. 2017

Jarosław Kałużny, DSc., DEng. - Faculty of Machines and Transport at Poznan University of Technology.

e-mail: Jaroslaw.Kaluzny@put.poznan.pl

\begin{abstract}
Aleksander Stepanenko, MEng. - Faculty of Machines and Transport at Poznan University of Technology.

e-mail: Stepanenko@wp.pl.
\end{abstract}
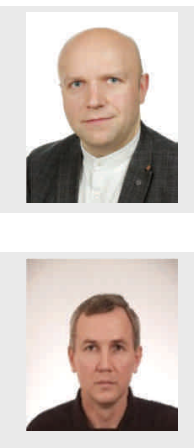

Bartosz Gapiński, DEng. - Faculty of Mechanical Engineering and Management at Poznan University of Technology.

e-mail: Bartosz.Gapinski@put.poznan.pl

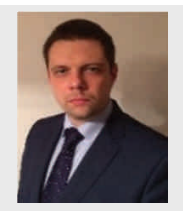

Adam Piasecki, DEng. - Faculty of Mechanical Engineering and Management at Poznan University of Technology.

e-mail: Adam.Piasecki@put.poznan.pl

[14] MERKISZ, J., PIELECHA, J., BIELACZYC, P., WOODBURN, J. Analysis of emission factors in RDE tests as well as in NEDC and WLTC chassis dynamometer tests. SAE Technical Paper. 2016, 2016-01-0980.

[15] MERKISZ, J., PIELECHA, J. Selected experiences in RDE in Polish reality for different combustion engine applications. 4rd International Conference "Real Driving Emissions", Berlin 25-27.10.2016.

[16] MERKISZ, J., PIELECHA, J. Selected remarks about RDE test. Combustion Engines. 2016, 166(3), 54-61.

[17] NOORDUIN W.L. et al. Rationally designed complex, hierarchical microarchitectures. Science. 2013, 5.

[18] OTTLICZKY, E., VOIGT, M., WEIMAR, H.J., WEISS, E. Stahlkolben für PKW-Dieselmotoren. MTZ. 2011, 10.

[19] PROFITO, F.J., ZACHARIADIS, D.C., TOMANIK, E. One dimensional mixed lubrication regime model for textured piston rings. Proceedings of COBEM. 2011.

[20] RAMACHANDRAN, S., STIMMING, U. Well to wheel analysis of low carbon alternatives for road traffic. Energy \& Environmental Science. 2015, 8, 3313-3324.

[21] USMAN, A., PARK, C.W. Modeling and simulation of frictional energy loss in mixed lubrication of a textured piston compression ring during warm-up of spark ignition engine. International Journal of Engine Research. 2017, 18(4), 293-307.

[22] REN, Z. et al. Hierarchically nanostructured materials for sustainable environmental applications. Frontiers in Chemistry. 2013, 1(18), 1-22.

Prof. Jerzy Merkisz, DSc., DEng. - Faculty of Mechanical Engineering at University of Technology.

e-mail: Jerzy.Merkisz@put.poznan.pl

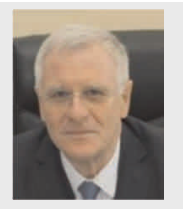

Emil Wróblewski, MEng. - Faculty of Machines and Transport at Poznan University of Technology.

e-mail: Emil.Z.Wroblewski@doctorate.put.poznan.pl
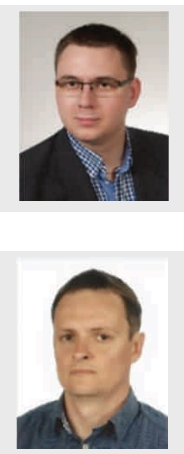

Dawid Gallas, MSc. - Faculty of Machines and Transport at Poznan University of Technology.

e-mail: Dawid.P.Gallas@doctorate.put.poznan.pl

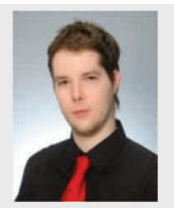

